Article

\title{
The Value of International Business Education: How to Achieve Transformative Learning for Students
}

\author{
Yongsun Paik \\ ${ }^{1}$ Loyola Marymount University, USA \\ Keywords: transformative learning, breadth, interdisciplinary curriculum, ib education \\ https://doi.org/10.46697/001c.13439
}

\section{AIB Insights}

Vol. 20, Issue 1, 2020

The slowdown of the global economy exacerbated by the COVID-19 pandemic provides us an important opportunity to reflect upon the current status and future prospect of international business education. In order to reaffirm the value of international business as a distinct discipline, this article asks the three key questions: Why do we teach international business? What do we teach? How do we teach? International business educators are responsible for preparing students to become future global leaders and citizens through transformative pedagogy that combines the acquisition of knowledge and skills across multidisciplinary disciplines, with meaningful and practical experiences within the subjects they are learning.

\section{INTRODUCTION}

The presence and credibility of international business education seems to be diminishing, at least in the US, as many American schools are removing or downsizing international business majors and/or courses from their curricula. Globalization has retreated in the midst of increased protectionism, as illustrated by the US-China trade war and Brexit. With the slowdown of globalization, the value of international business education is also being challenged and questioned, and may even be in crisis. As the Chinese word for “crisis” (危機) represents, being made of the letters for 危險 (danger) and 機會 (opportunity), this development presents a great opportunity to redefine the identity and meaning of international business education. It is an opportune time to reflect upon the current status and future challenges of international business education, and to develop compelling and convincing arguments for support. Having clear educational goals and objectives provides not only justification, but also a foundation for improving the quality of international business education. This article discusses the values and aims of international business education by addressing three key questions facing international business educators: Why should international business courses be part of the curriculum? What needs to be taught in these courses? How should these courses be taught? Table 1 summarizes the educational dimensions of each of these questions along with actionable recommendations.

\section{DISTINCTIVE GOAL OF INTERNATIONAL BUSINESS EDUCATION: BREADTH OR DEPTH?}

The first question above concerns what the goal and learning outcomes of international business education should be. This is the fundamental question that international business educators must ask. The raison d'être of international business education lies in helping students become respectable global leaders and citizens through transformative learning. Global leaders need to continue improving their ability to interpret and evaluate global issues. In order to achieve this goal, they should be provided with lead- ership development and global experience opportunities. Global citizens are people who are open and excited about working with people from other cultures. As they value diversity and understand global issues, global citizens enjoy communicating with people from other countries, staying abreast of new developments around the world, and finding ways to improve the world. Global citizens see the world as a whole as they have a sense of belonging to a world community and comprehend how the world works in regards to politics, economics, technology and the environment.

The demand for a global workforce will continue to increase in developed countries as their populations age and their labor forces decline. To effectively address this challenge, more enlightened leaders who understand the dynamics of a global workforce are needed. As future global leaders and citizens, students will need to obtain the skills to manage employees and work with supervisors from other countries. To meet this goal, students require an education that will broaden their perspectives about the world through learning relevant contexts and contents. According to The New York Times (Schuetze, 2013), institutions that concentrate on preparing graduates with a broad skill set are gaining more recognition, regardless of their country or region. Thus, international business education should focus on breadth rather than depth of learning, and be taught as an interdisciplinary subject. Breadth of learning represents a more holistic approach to education as it seeks a more horizontal understanding across a number of disciplines.

However, the current format of business education generally attends to depth rather than breadth of learning and makes it difficult for students to cultivate a global mindset. Business school curricula typically focuses on functional courses such as accounting, finance, and marketing to help students acquire practical knowledge and specific skills in each business area. Many business professors also tend to prefer to cover their subjects as deeply as possible to help students build their careers as specialists in particular subjects. Meanwhile, international business education is losing not only its recognition but also its place as international business subjects are increasingly integrated into relevant functional courses, such as international finance and international marketing. Skeptics even question the need for 
Table 1. Value of International Business Education: Three Key Dimensions and Action Items

\begin{tabular}{|c|c|c|}
\hline $\begin{array}{l}\text { Key } \\
\text { Questions }\end{array}$ & Educational Dimensions & Actionable Recommendations \\
\hline \multirow[t]{4}{*}{ Why } & Goals: & \\
\hline & Developing Global Leaders \& Citizens & Focusing on breadth of learning \\
\hline & & Improving the ability to interpret and evaluate global issues \\
\hline & & $\begin{array}{l}\text { Providing leadership development and global experience } \\
\text { opportunities }\end{array}$ \\
\hline \multirow[t]{4}{*}{ What } & Contents: & \\
\hline & $\begin{array}{l}\text { Obtaining Comprehensive Understanding of } \\
\text { Different Disciplines }\end{array}$ & Introducing interdisciplinary curriculum \\
\hline & & Developing cross-cultural intelligence \\
\hline & & Learning foreign languages \\
\hline \multirow[t]{4}{*}{ How } & Pedagogy: & \\
\hline & Achieving Transformative Learning & Aligning learning outcomes with course projects \\
\hline & & Expanding project-based experiential learning \\
\hline & & $\begin{array}{l}\text { Developing the global mindset through study abroad or short- } \\
\text { term field trip programs }\end{array}$ \\
\hline
\end{tabular}

an international business curriculum, claiming that every business is now potentially international in our global economy. To be frank, such criticism is not new; in fact, international business has always struggled with its identity as an independent discipline. Many faculty at business schools simply regard international business courses as an extension of regular functional courses with added international content. They still adhere to an old integration model in which international business topics are incorporated into functional courses (Thanopoulos \& Vernon, 1987). But the nature of international business is clearly interdisciplinary. And to be in tune with this reality, international business instruction should be broad-based, interdisciplinary, and involve functionally integrated learning, rather than focus on more isolated depth of learning in acquiring functional fundamentals and more advanced tools. The breadth of learning is more effective and appropriate in the context of international business that deals with real-world problems, which is more complex and complicated than domestic issues, that require an application of wider rather than deeper knowledge.

\section{KNOWLEDGE AND SKILLS REQUIRED TO BECOME GLOBAL LEADERS}

To achieve these distinct goals, what should the main contents of international business courses be? What topics should be included and taught in international business? It may not be easy to reach a consensus on these questions. Nonetheless, what should be taught in international business courses becomes rather apparent once the goal of international business education is clearly understood. The course content should support the goal of developing global leaders and citizens with a global mindset. Table 1 includes three actionable recommendations in terms of the contents of international business education. First, the contents of international business education should be congruent with the goal of breadth of learning. Accordingly, interdisciplinary curriculum needs to be introduced to help students develop cognitive and analytical skills to recognize, interpret and evaluate complex and complicated international business issues and developments. The recent trade dispute between the US and China illustrates how critical it is for students to possess broad content as well as context knowledge in order to fully understand the key issues at stake.

One view states that the US-China trade war was triggered by President Donald Trump, who believes that the huge trade deficit of the US is due to unfair trade practices and theft of American intellectual property by China. However, some pundits believe that the confrontation of the two largest economies is probably more than a mere trade dispute. They contend that the escalating tension between the US and China should be understood in the broader context of a geopolitical clash in Asia where the US countered China's One Belt One Road project with its own Indo-Pacific initiative in order to curb China's increasing influence over its neighboring countries. Along with knowledge of the context, students need to acquire appropriate content knowledge from multiple disciplines in order to grasp the root cause of the deficit: what balance of payments is, how a trade deficit occurs, and how it is financed. In addition to knowledge in macroeconomics, students can analyze this issue more critically if they understand different types of capitalism and consumption behaviors. While the US practices individual capitalism that highly values creativity and the innovative capacity of a particular person, China practices communitarian capitalism that promotes sharing technology for the sake of the country's economic growth. In fact, this practice may be viewed as the origin of the controversy over intellectual property rights protection between the two countries. Another potential explanation for the US's huge trade deficit exists in understanding sociocultural factors, i.e., a predominant indulgence culture in which Americans tend to engage in activities to enjoy life now rather than saving for the future. Buffett (2003) described the US as Squanderville in his metaphor to illustrate Americans' appetite for mass consumption, in contrast to China as Thriftville which works hard to produce and export goods to satisfy the American demand.

The above example illustrates that the true value of international business education lies in a holistic approach 
across multiple disciplines to get to the bottom of the issues under investigation and demonstrates how breadth of learning can be actually converted to depth of learning. Otherwise, international business education could fall into the pitfall of simply being a replication of an international finance course that typically focuses on China's manipulation of the yuan as the main cause of the trade friction between the US and China. International business educators should demonstrate a comprehensive understanding of the multiple disciplines to be able to teach students to broaden their perspectives and to help them develop the ability to grasp, analyze and evaluate key international business issues.

Second, global leaders should be equipped with crosscultural intelligence in order to effectively communicate and cultivate emotional attachment with the global workforce. Soft skills are as important as hard skills, and maybe even more critical when managing people imbued with different values and norms. In order to mitigate implicit bias and stereotyping, it is essential not only to develop crosscultural intelligence and cultural humility but also to acquire a certain level of foreign language proficiency. Language proficiency is a particularly challenging issue for international business education in the US given that English is the most widely used global business language, and there has been little need to learn foreign languages. However, the situation is rapidly changing as American dominance in the global economy continues to diminish. According to findings from the American Council on the Teaching of Foreign Languages (ACTFL), "Nine out of ten US employers report a reliance on US-based employees with language skills other than English. Nearly one in four employers acknowledge losing or being unable to pursue a business opportunity due to deficiency in foreign language skills" (ACTFL, 2019: 3, 4). Since it is a long process to develop crosscultural competence, language proficiency, and leadership skills, international business courses cannot provide all the education that global leaders will need but should lay a foundation for developing leaders to continue to build on.

\section{HOW TO ACHIEVE TRANSFORMATIVE LEARNING}

The final responsibility of international business educators involves delivery of the instructional content. For example, it is difficult to learn culture in a classroom setting without firsthand experience. Therefore, educators must think about the vehicles through which course content is most effectively delivered. There are many different ways in which students can develop an ability to connect theoretical and conceptual knowledge to practical know-how and skills. Transformative learning makes students change the way they think and view the world based on critical reflection on experiences. How should practical pedagogy be designed to ensure transformative learning for students? Table 1 summarizes the three actionable recommendations to answer to this question. First, it is critical to align the learning outcomes of an international business course with its inclass projects. Educators should have a clear understanding of how the project will meet the learning objectives of the course before assigning it to students.

Second, experiential-learning involves acquiring firsthand experiences and is crucial for achieving higher levels of learning. Project-based learning within international and multicultural contexts has become a very popular teaching method, as it develops the global mindset and international business acumen through firsthand learning experiences. However, without proper understanding of the contexts and contents related to the projects, the benefit of project-based learning would be limited. Educators can make it possible for transformative learning to occur through study abroad programs, group projects, case analyses, and simulations, as these methods help students examine concepts in a realworld context and stimulate new discovery. In order to facilitate transformative learning, international business education should provide an opportunity for self-examination and experiential learning. Self-examination involves introspection and self-awareness. Global leaders need to have an accurate assessment of their interests, concerns, and current level of cultural literacy (Cohen, 2010). They will identify their areas of weakness through this process in terms of context and contents.

In particular, study abroad programs provide students with a great opportunity for experiential learning through cultural immersion and internship opportunities. However, to maximize the impact on learning, students likewise need to understand the context, including the history and institutions of the country they are visiting, as well as the specific contents related to the subjects they are studying. One example of a successful short-term faculty-led study abroad program at Loyola Marymount University is the Global Sustainability: Challenges and Prospects in East Asia course. In this course, which is open to juniors and seniors of all majors, students first spend a semester acquiring relevant knowledge of content and context prior to ending the course with a two-week field trip to East Asia to observe best business practices in sustainability. In the semester prior to their field trip, students learn about the contents, i.e., key elements of sustainability at both the strategic and functional level, as well as the contexts, i.e., the political, economic, and socio-cultural environments of the countries they later visit. Furthermore, students are encouraged to group with other students from different disciplines (e.g., business, liberal arts, and science and engineering) to achieve interdisciplinary learning on their projects. Hence, even a short-term study abroad program can produce transformational learning if the course is deliberately designed to induce a paradigm shift among students (Hallows, Porter Wolf, \& Marks, 2011).

\section{CONCLUSION}

To conclude, international business is an intrinsically interdisciplinary subject and is not limited to the international dimensions of self-contained functional areas of business. The above analysis of the trade dispute between the US and China demonstrates that interdisciplinary breadth of learning in fact helps students acquire an in-depth understanding about the issue. It would be naïve and erroneous to assume that international business can be properly covered in traditional functional business courses. Instead, international business education pitfalls should be avoided by concentrating less on the functional business areas and shifting focus to providing education that is broad and transformative. We can achieve this by aligning experiential learning with the international business knowledge our students gain prior to participating in a study abroad program or real-world experiential project. Essentially, this is how transformative learning is achieved. It is the responsibility of international business educators to ensure that students develop interest in and keep abreast of globally significant issues, and aspire to work together to solve real world problems. Without a sense of belonging to the global 
village, major challenges such as global warming, conflict, and poverty cannot be effectively addressed. International business educators can and should play a vital role in pursuing these endeavors by educating students to become responsible global leaders and citizens through transformative pedagogy. This goal should indeed be the unique contribution and value of an international business education.

\section{ABOUT THE AUTHOR}

Yongsun Paik (Yongsun.Paik@lmu.edu) is a Professor of International Business and Management and Director of the
Center for International Business Education (CIBE) at Loyola Marymount University. He received his Ph.D. in International Business from University of Washington, Seattle, WA. He is the author of three books and has published more than 60 articles in major international business and management journals. His research focuses on global trade, international human resource management, business ethics and international entrepreneurship. 


\section{REFERENCES}

American Council on the Teaching of Foreign Languages (ACTFL). 2019. Making languages our business: Addressing foreign language demand among US employers. Alexandria, VA: ACTFL.

Buffett, W. 2003, October 26. America's growing trade deficit is selling the nation out from under us. Here's a way to fix the problem - and we need to do it now. Fortune.

Cohen, S. L. 2010. Effective global leadership requires a global mindset. Industrial and Commercial Training, 42(1): 3-10.
Hallows, K., Porter Wolf, P., \& Marks, M. A. 2011. Short - term study abroad: A transformational approach to global business education. Journal of International Education in Business, 4(2): 88-111.

Schuetze, C. F. 2013, October 28. Recruiters without borders: Companies scout globally. New York Times, NA(L).

Thanopoulos, J., \& Vernon, I. R. 1987. International business education in the AACSB schools. Journal of International Business Studies, 18(1): 91-98. 